\title{
Concentrations and distributions of Dechlorane Plus in environmental samples around a Dechlorane Plus manufacturing plant in East China
}

\author{
Qinghua Zhang $\cdot$ Chaofei Zhu $\cdot$ Haidong Zhang $\cdot$ \\ Pu Wang · Yingming Li - Daiwei Ren · \\ Guibin Jiang
}

Received: 14 December 2014/ Accepted: 28 January 2015/Published online: 18 March 2015

(C) Science China Press and Springer-Verlag Berlin Heidelberg 2015

\begin{abstract}
A comprehensive investigation into the occurrence of Dechlorane Plus (DP) in environmental samples around a DP manufacturing plant in East China was performed. The total syn-DP and anti-DP concentrations found in the soil, sediment, active air, and passive air samples were $0.50-2,315 \mathrm{pg} / \mathrm{g}$ dry weight $(\mathrm{dw}), 0.32-20.5 \mathrm{ng} / \mathrm{g} \mathrm{dw}$, $5.52-3,332 \mathrm{pg} / \mathrm{m}^{3}$, and $1.00-4,560 \mathrm{pg} / \mathrm{m}^{3}$, respectively. There were consistent trends in the spatial distributions of DP in the soil and air samples, with the DP concentrations decreasing dramatically as the distance from the plant increased. The mean anti-DP isomer fractional abundances $\left(f_{\text {anti }}\right)$ in the soil, sediment, active air, and passive air samples were $0.67,0.68,0.70$, and 0.64 , respectively. These $f_{\text {anti }}$ values were consistent with the $f_{\text {anti }}$ value for the technical DP produced in the DP manufacturing plant (0.68), meaning that the DP had been released during the local DP production activities.
\end{abstract}

Keywords Dechlorane Plus · Soil · Sediment · Air · Manufacturing plant

Electronic supplementary material The online version of this article (doi:10.1007/s11434-015-0768-1) contains supplementary material, which is available to authorized users.

Q. Zhang $(\bowtie) \cdot$ C. Zhu $\cdot$ P. Wang · Y. Li · D. Ren · G. Jiang State Key Laboratory of Environmental Chemistry and Ecotoxicology, Research Center for Eco-Environmental Sciences, Chinese Academy of Sciences, Beijing 100085, China e-mail: qhzhang@rcees.ac.cn

H. Zhang

Department of Geography and Environment, Baoji University of Arts and Sciences, Baoji 721013, China

\section{Introduction}

The chlorinated flame-retardant Dechlorane Plus (DP; $\mathrm{C}_{18} \mathrm{H}_{12} \mathrm{Cl}_{12}$ ), which is used as a substitute for Dechlorane (also called Mirex), is widely used in hard plastic electrical connectors in televisions and computer monitors, wire coatings, and furniture [1]. DP has been identified by the United States Environmental Protection Agency (USEPA) as being a high production volume chemical, and at least $450,000 \mathrm{~kg} /$ year is produced or imported into the USA [2]. Even though DP has been produced and used for several decades, it was not first detected in environmental samples until 2006 [3]. DP has been found to have similar properties to persistent organic pollutants (POPs), and these properties include its bioaccumulation potential [4-7], its persistence in the environment $[8,9]$, and its potential for long-range transport to remote regions [10]. However, limited toxicity data for DP have so far been obtained [11, 12]. DP was considered as a candidate for evaluation under Annex D of the United Nations Stockholm Convention on POPs in 2011 [2].

The production of DP is considered to be the most important source of DP emissions to the environment in certain regions. Hoh et al. [3] found relatively high DP concentrations in sediment samples from Lake Ontario, downstream of a DP manufacturer (Oxychem, New York, USA). Wang et al. [13] determined DP concentrations in samples around a DP facility in China and found very high DP concentrations at sites near the facility. In another study of DP in soil from the same area, the factory was found to be the dominant point source of DP pollution to the area surrounding the factory [14]. However, the DP concentrations that were found in the environmental samples analyzed in these two studies were very different, and this needs to be investigated further. To the best of our 
knowledge, little information is available to systematically assess environmental contamination caused by DP manufacturing plants. The influence of a DP production plant on the surrounding environment and on human health still needs to be investigated further.

In the study presented here, actively and passively collected air samples, soil samples, and surface sediment samples were collected in the vicinity of a DP production facility in East China to allow the concentrations and spatial distribution of DP in the area surrounding the DP production facility to be assessed. The potential impact of the DP production processes on the environment surrounding the facility was also assessed.

\section{Materials and methods}

\subsection{Materials}

All solvents and reagents were of analytical or pesticide grade. $n$-Hexane and dichloromethane were purchased from J.T. Baker (Phillipsburg, NJ, USA). Nonane (chromatographic grade) was purchased from Sigma-Aldrich (St Louis, MO, USA). Silica gel 60 (70-230 mesh) was purchased from Merck (Darmstadt, Germany). Anhydrous sodium sulfate was purchased from Beijing Chemical Factory (Beijing, China). Individual syn-DP and anti-DP standards ( $50 \mu \mathrm{g} / \mathrm{mL}$ in toluene; purity $>95 \%$ ) and ${ }^{13} \mathrm{C}_{12}$-labeled PCB-138 and ${ }^{13} \mathrm{C}_{12}$-labeled PCB-209 standards were supplied by Wellington Laboratories (Guelph, Canada).

\subsection{Sample collection}

The sampling area was around a DP production facility in East China. The area has a subtropical monsoon climate. The annual average temperature is $14.1-14.5{ }^{\circ} \mathrm{C}$, and the wind comes predominantly from the east and southwest. The plant produces DP at a rate of about $500 \mathrm{t} / \mathrm{year}$. Three types of commercial DP products, DP-25, DP-35, and DP515 , are produced in the plant. The products have the same ingredients but different particle sizes, and the products are similar to products that are made by Oxychem (http://www. oxy.com/OurBusinesses/Chemicals/Products/Documents/ dechloraneplus/dechlorane_plus.pdf.).

\subsubsection{Active air sampling}

A total of seven air samples were collected using highvolume air samplers (ECHO HiVol, TCR., Italy). Each sample was collected over a period of $24 \mathrm{~h}$ in September 2011 in zones used for different functions around the sampling area. The samples were collected following the revised USEPA Method TO-9A. When collecting a sample, air was passed through a glass fiber filter $(10.16 \mathrm{~cm}$ diameter) and a polyurethane foam (PUF) plug $(6.3 \mathrm{~cm} \mathrm{di-}$ ameter and $7.6 \mathrm{~cm}$ long) to collect the particle-bound chemicals and the gaseous chemicals, respectively. The glass fiber filters were baked at $450{ }^{\circ} \mathrm{C}$ before use to remove organic contaminants, and the PUF plugs were extracted with acetone and then $n$-hexane in an accelerated solvent extraction (ASE) system (ASE300; Dionex, Sunnyvale, CA, USA). The ASE was performed at $100{ }^{\circ} \mathrm{C}$ and $1,500 \mathrm{psi}(1 \mathrm{psi}=6.895 \mathrm{kPa})$ for two static extraction cycles. The PUF plugs were then dried under vacuum in a desiccator and stored in sealed bags. The detailed sampling procedure has been published previously [15].

\subsubsection{Passive air sampling}

PUF disks were used for passive air sampling. The preparation, use, and analysis procedures for the PUF disks are described in detail elsewhere [16, 17]. Briefly, the PUF disks were extracted before use with acetone and then with hexane in an ASE system (at a pressure of 1,500 psi and a temperature of $100{ }^{\circ} \mathrm{C}$, with two cycles of heating for $5 \mathrm{~min}$, a static temperature for $8 \mathrm{~min}$, a flushing volume of $60 \mathrm{vol} \%$, and a purge of $120 \mathrm{~s}$ ). The sampling chambers were washed and rinsed with acetone before being assembled and a PUF disk added. All of the procedures were performed using clean gloves, and the PUF disks were handled using acetone-rinsed tongs. A PUF disk PAS was deployed at each sampling site for a period of 12 months, from September 2011 to August 2012, covering the four distinct seasons that occur in the sampling area, i.e., fall (September, October, and November), winter (December, January, and February), spring (March, April, and May), and summer (June, July, and August). The PUF disk in each PAS was replaced with a fresh PUF disk every 3 months. When a PUF disk was retrieved, it was sealed in a container and taken back to the laboratory, where it was stored frozen until it was extracted and analyzed.

\subsubsection{Soil and sediment sampling}

A total of 15 soil and seven sediment samples were collected in September 2011. The soil samples were collected using a stainless steel spade, and the sediment samples were collected using a stainless steel grab sampler. The samples were stored in a freezer at $-20^{\circ} \mathrm{C}$ until they were analyzed. The sampling locations are shown in Fig. S1 (online).

\subsection{Sample preparation}

The samples were prepared for DP analysis following procedures that were used in our previous studies [18], with minor alterations. Briefly, an air sample was spiked with 
$1 \mathrm{ng}$ of ${ }^{13} \mathrm{C}_{12}$-labeled PCB-209, which was used as a surrogate standard, then extracted in the ASE system with a $1: 1 \mathrm{v}: \mathrm{v}$ mixture of hexane and dichloromethane. The extract was concentrated to about $2 \mathrm{~mL}$ and then passed through a multilayer silica column (containing, from the bottom to the top, $1 \mathrm{~g}$ neutral silica, $4 \mathrm{~g}$ basic silica, $1 \mathrm{~g}$ neutral silica, $8 \mathrm{~g}$ acid silica, $2 \mathrm{~g}$ neutral silica, and $4 \mathrm{~g}$ anhydrous sodium sulfate). The eluate was concentrated to $\sim 20 \mu \mathrm{L}$ and spiked with $1 \mathrm{ng}$ of ${ }^{13} \mathrm{C}_{12}$-labeled PCB-138, which was used as an injection standard, and then analyzed by gas chromatography-mass spectrometry.

The soil and sediment samples were freeze-dried, ground, and then extracted using the ASE system. The extraction conditions and cleanup procedures were similar to those described above for the air samples, except that the extraction temperature was $150{ }^{\circ} \mathrm{C}$.

\subsection{Instrumental analysis}

The sample extracts were analyzed using a gas chromatography-mass spectrometry instrument (2010 Ultra; Shimadzu, Kyoto, Japan) with an electron capture negative ionization ion source. A $1-\mu \mathrm{L}$ aliquot of a sample extract was injected into the gas chromatograph in splitless mode, and the mass spectrometer was operated in selected ion monitoring mode. The injection port and the transfer line were held at $285^{\circ} \mathrm{C}$. The ion source temperature was $200{ }^{\circ} \mathrm{C}$. The carrier gas was helium, and the reagent gas was methane. A $15-\mathrm{m}$ DB-5MS capillary column $(0.25 \mathrm{~mm}$ i.d., $0.1 \mu \mathrm{m}$ film thickness; Agilent Technologies Inc., Santa Clara, CA, USA) was used to achieve the chromatographic separation, and the carrier gas was used at a constant flow rate of $1 \mathrm{~mL} /$ min. The gas chromatograph oven temperature program started at $100{ }^{\circ} \mathrm{C}$, which was held for $4 \mathrm{~min}$, then increased at $8{ }^{\circ} \mathrm{C} / \mathrm{min}$ to $150{ }^{\circ} \mathrm{C}$, which was held for $4 \mathrm{~min}$, and finally increased at $12{ }^{\circ} \mathrm{C} / \mathrm{min}$ to $300{ }^{\circ} \mathrm{C}$, which was held for $13 \mathrm{~min}$. The ions that were monitored were $\mathrm{m} / \mathrm{z} 653.8$ and 651.8 for DP, m/z 369.7 and 371.7 for ${ }^{13} \mathrm{C}_{12}$-labeled PCB138 , and $\mathrm{m} / \mathrm{z} 507.9$ and 509.9 for ${ }^{13} \mathrm{C}_{12}$-labeled PCB-209.

The total organic carbon (TOC) contents in the soil and sediment samples were determined using a Solids TOC Analyzer (OI Analytical, College Station, TX, USA) with a non-dispersive infrared detector. The TOC determination method is described in detail elsewhere [19]. Briefly, a sample was wetted with a $5 \% \mathrm{v}$ :v phosphoric acid solution and then heated to $250{ }^{\circ} \mathrm{C}$ to remove the inorganic carbon. The sample was then combusted at $900{ }^{\circ} \mathrm{C}$ for $6 \mathrm{~min}$ to determinate the TOC content.

\subsection{Quality assurance/quality control}

One laboratory blank was processed in parallel with each batch of 10 samples, and no DP isomers were detected in these blanks. The ${ }^{13} \mathrm{C}_{12}$-labeled PCB-209 recoveries for all of the samples ranged from $79.2 \%$ to $108 \%$. An analyte was identified if the retention time of the peaks for the appropriate ions was within $0.1 \mathrm{~min}$ of the retention time of the standard compound. The limit of detection was defined as the concentration giving a peak with a signal-to-noise ratio of 3 . The mean method detection limits for syn-DP and anti-DP were 0.016 and $0.023 \mathrm{ng} / \mathrm{g} \mathrm{dw}$ in soil, 0.018 and $0.022 \mathrm{ng} / \mathrm{g} \mathrm{dw}$ in sediment, and 0.56 and $0.63 \mathrm{pg} / \mathrm{m}^{3}$ in air, respectively.

\section{Results and discussion}

\subsection{Concentrations and spatial distribution of DP in air}

The concentrations of the two DP isomers and of the total DP (the syn-DP plus the anti-DP concentrations) found in the air samples around the DP manufacturing facility are shown in Table S1 (online, for the actively collected samples) and Table S2 (online, for the passively collected samples). The total DP concentrations in the active air samples ranged from 5.52 to $3,332 \mathrm{pg} / \mathrm{m}^{3}$. DP was detected in both the particle phase and the gas phase fractions of the samples, but more than $95 \%$ of the DP was found in the particle phase, which was consistent with the results of studies by Hoh et al. [3] and Wang et al. [14].

The spatial distribution of DP in air around the sampling area is shown in Fig. S2 (online). As expected, the highest DP concentration $\left(3,332 \mathrm{pg} / \mathrm{m}^{3}\right)$ was found at sampling site P7 (for passive air sampling), which was inside the DP plant. This concentration was much lower than the highest DP concentration $\left(26,734 \mathrm{pg} / \mathrm{m}^{3}\right)$ that was found in a study by Wang et al. [14]. High DP concentrations were detected at four other sites, P1, P4, P6, and P8, which were all around the plant. The lowest concentration $\left(5.52 \mathrm{pg} / \mathrm{m}^{3}\right)$ was found at site $\mathrm{P} 2$, which was some distance from the plant.

The DP concentration in a passive air sample was calculated by dividing the amount of DP collected on a PUF disk by the effective air volume that was sampled. The effective air volume was calculated by multiplying the deployment time (typically $\sim 90 \mathrm{~d}$ ) by a particle-phase sampling rate of $3.5 \mathrm{~m}^{3} / \mathrm{d}$ [15]. DP was detected in all of the passively collected air samples $(n=40)$, and the concentrations ranged from 1.0 to $4,560 \mathrm{pg} / \mathrm{m}^{3}$ (Table S2 online). The DP concentrations in the samples collected in the winter were a little higher than in the samples collected in the other seasons, but there were no significant differences $(P>0.05$ for all of the seasons) between the concentrations found in the samples collected in the different seasons (Fig. 1). 


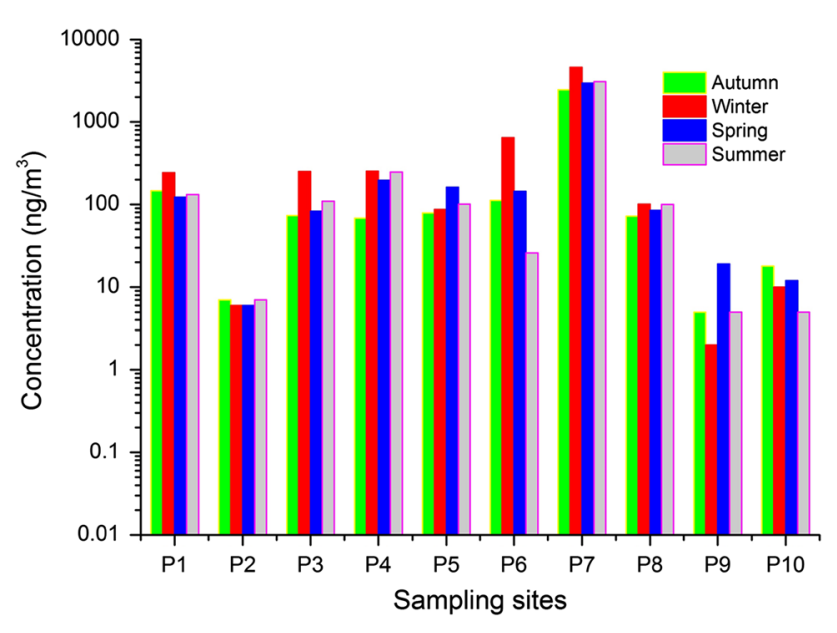

Fig. 1 Comparison of the total DP levels in the four seasons

The DP concentrations in the passive air samples showed similar spatial trends to the DP concentrations in the active air samples, and the highest concentrations were found at sampling site P7. Relatively high concentrations were also found in the samples from sites P3-P6 and P8, which were in urban areas, while the concentrations were lower in the samples from rural sites $(\mathrm{P} 2, \mathrm{P} 9$, and $\mathrm{P} 10)$. This is consistent with the observations made by Ren et al. [20], who found significantly higher DP concentrations in air in urban areas (median $\left.15 \mathrm{pg} / \mathrm{m}^{3}\right)$ than in rural areas $\left(4 \mathrm{pg} / \mathrm{m}^{3}\right)$.

\subsection{Concentrations and spatial distribution of DP in soil}

All the soil samples contained detectable DP concentrations, and the concentrations ranged from 0.50 to $2,315 \mathrm{ng} /$ $\mathrm{g} \mathrm{dw}$. The total DP concentrations in the soil samples and the TOC contents of the samples are presented in Table S3 (online). The spatial distribution of DP in the soil around the DP plant is shown in Fig. 2. The highest DP

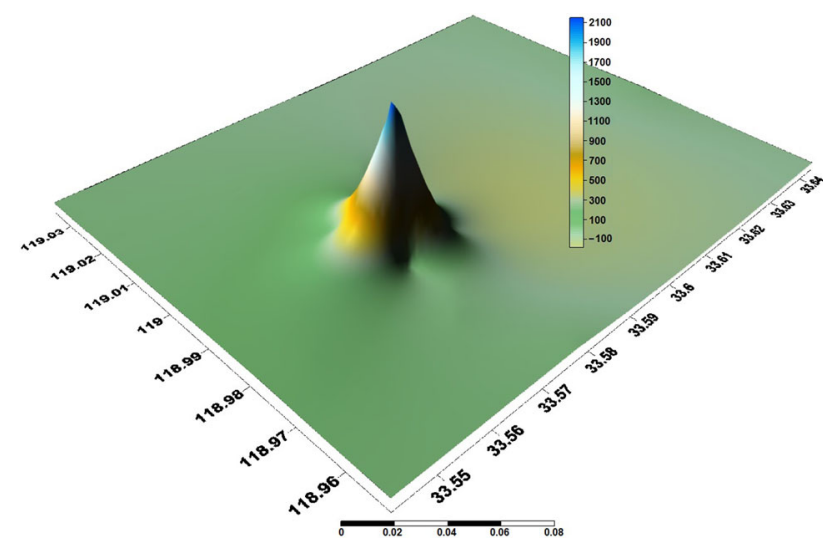

Fig. 2 Spatial distribution of DP concentrations in soil in the sampling area concentration in soil $(2,315 \mathrm{ng} / \mathrm{g}$ ) was found at site $\mathrm{S} 1$ (for soil sampling), which was inside the plant. This was in the same order of magnitude as the DP concentration found at a sampling site close to the plant [13], but much lower than the concentrations found by Wang et al. [14]. High DP concentrations were found in samples from sites S1, S5, S8, S9, and S13, which were close to the plant. The lowest DP concentration in soil $(0.497 \mathrm{ng} / \mathrm{g} \mathrm{dw})$ was found at site $\mathrm{S} 4$, which was $7.6 \mathrm{~km}$ from the plant.

The $\log K_{\text {ow }}$ value for DP is rather high (9.3 for both the syn-DP and anti-DP stereoisomers), so both DP isomers could easily become sorbed by organic matter in environmental media and would eventually be partitioned between the organic matter and other phases in the environmental media [4]. However, no correlation was found between the TOC contents of the soil samples and the DP concentrations in the samples. As Zhao et al. [21] stated, besides the TOC content of soil, the land use, wet deposition, degradation of DP in the environment, and atmospheric transport of DP could all affect the DP distribution in soil and sediment. In addition, the source of DP emissions could clearly affect the distribution of contaminants in the area surrounding the source, and this could disturb the balance between the pollutant concentrations in the soil organic matter and the other soil components.

\subsection{Spatial distribution of DP in sediment}

The total DP concentrations in the sediment samples ranged from 0.32 to $20.5 \mathrm{ng} / \mathrm{g} \mathrm{dw}$, and the mean concentration was $5.23 \mathrm{ng} / \mathrm{g} \mathrm{dw}$ (Table S4 online). DP concentrations in river and lake sediment from China and the North American Great Lakes area have been determined in several studies. Sediment samples from China that have been analyzed have been found to contain mean DP concentrations of $0.05-0.12 \mathrm{ng} / \mathrm{g} \mathrm{dw}$ (in Harbin) [22], $3 \mathrm{ng} / \mathrm{g} \mathrm{dw}$ (in Dalian) [23], $2.46 \mathrm{ng} / \mathrm{g} \mathrm{dw}$ (in the coastal area of Dalian) [24], $0.045 \mathrm{ng} / \mathrm{g} \mathrm{dw}$ (in Yellow Sea coastal sediments) [21], and 2-8 ng/g dw (in Huai' an) [14]. Sediment samples from the North American Great Lakes that have been analyzed have been found to contain mean DP concentrations of $0.33 \mathrm{ng} / \mathrm{g} \mathrm{dw}$ (Lake Superior) [25], $0.55 \mathrm{ng} / \mathrm{g} \mathrm{dw}$ (Lake Michigan) [26], $0.87 \mathrm{ng} / \mathrm{g} \mathrm{dw}$ (Lake Huron) [25], $5 \mathrm{ng} / \mathrm{g} \mathrm{dw}$ (Lake Erie) [26], and $1.2 \mathrm{ng} / \mathrm{g} \mathrm{dw}$ (Lake Erie) [25]. These concentrations are generally lower than the concentrations that we found in sediment samples from our study area. However, a mean DP concentration of $7,590 \mathrm{ng} / \mathrm{g}$ was found in sediment from a reservoir close to an e-waste recycling plant in South China [27], and mean concentrations of approximately $300 \mathrm{ng} / \mathrm{g} \mathrm{dw}$ [26] and $26 \mathrm{ng} / \mathrm{g} \mathrm{dw}$ [25] have been found in sediment from Lake Ontario, and these concentrations were much higher than the concentrations we found in our study area. 
The highest DP concentration in sediment was found at site Se-1, which was near a drainage outlet from the DP plant. This indicates that wastewater from the DP plant might supply DP to the surrounding water bodies.

\subsection{Profile of the DP isomers}

The anti-DP fractional abundance $\left(f_{\text {anti }}\right)$ is generally used to assess the fate and distribution of DP in the environment. Commercial DP products contain about $65 \%$ anti-DP and $35 \%$ syn-DP, giving an $f_{\text {anti }}$ value of 0.65 [1, 28]. However, an $f_{\text {anti }}$ value of 0.75 for a commercial DP product has been reported [1], suggesting that the isomer ratio can vary substantially during production [3]. Commercial DP products from the DP manufacturing plant in our study area were analyzed, and their $f_{\text {anti }}$ values were $0.68 \pm 0.01$ $(n=4)$.

The mean $f_{\text {anti }}$ values for the soil, sediment, and air samples that were analyzed are shown in Fig. 3. The $f_{\text {anti }}$ values in the passively collected air samples ranged between 0.57 and 0.71 (mean 0.64). The mean $f_{\text {anti }}$ value was slightly lower than the $f_{\text {anti }}$ value for the commercial product produced at the plant in the study area but similar to the $f_{\text {anti }}$ values found in ambient air samples collected in other urban and rural areas in China [20] and at sites near Niagara Falls [3]. Furthermore, the mean $f_{\text {anti values in the }}$ soil, sediment, and actively collected air samples were $0.67,0.68$, and 0.70 , respectively, and these were similar to the $f_{\text {anti }}$ value for the commercial product. This suggests that both DP isomers are stable in the environment and that no obvious stereoselective process has occurred in the environment around the production plant.

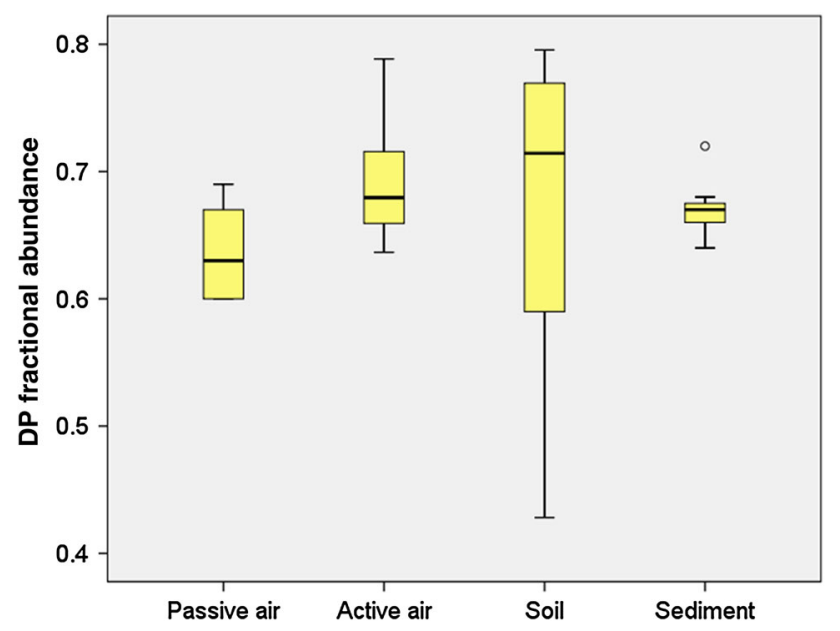

Fig. 3 DP fractional abundance $\left(f_{\text {anti }}\right)$ values for the soil, sediment, and air samples

\section{Conclusions}

The concentrations and distribution of DP in the air, soil, and sediment around a DP manufacturing plant were determined. The highest DP concentrations were found in samples within the grounds of the plant, and the DP concentrations decreased as the distance of the sampling site from the plant increased. The isomer profiles showed that anti-DP was the predominant isomer, and the $f_{\text {anti }}$ values in the environmental media samples were close to the $f_{\text {anti }}$ value in the commercial products produced at the plant, indicating that the DP production activities release DP to the environment around the plant. The results provide further confirmation that DP can potentially be transported from a production facility to the surrounding environment. The results will be of use when assessing the environmental impacts of a DP manufacturing plant on its surrounding environment.

Acknowledgments This work was supported by the Strategic Priority Research Program of the Chinese Academy of Sciences (XDB14010100), "One-Three-Five" Strategic Planning of Chinese Academy of Sciences (YSW2013B01), and the National Natural Science Foundation of China (21321004, 21277165 and 21107122).

Conflict of interest The authors declare that they have no conflict of interest.

\section{References}

1. Qiu X, Marvin CH, Hites RA (2007) Dechlorane plus and other flame retardants in a sediment core from Lake Ontario. Environ Sci Technol 41:6014-6019

2. Sverko E, Tomy GT, Reiner EJ et al (2011) Dechlorane plus and related compounds in the environment: a review. Environ Sci Technol 45:5088-5098

3. Hoh E, Zhu LY, Hites RA (2006) Dechlorane plus, a chlorinated flame retardant, in the Great Lakes. Environ Sci Technol 40:1184-1189

4. Tomy GT, Pleskach K, Ismail $\mathrm{N}$ et al (2007) Isomers of dechlorane plus in Lake Winnipeg and Lake Ontario food webs. Environ Sci Technol 41:2249-2254

5. Tomy GT, Thomas CR, Zidane TM et al (2008) Examination of isomer specific bioaccumulation parameters and potential in vitro hepatic metabolite of syn- and anti-Dechlorane Plus isomers in juvenile rainbow trout (Oncorhynchus mykiss). Environ Sci Technol 42:5562-5567

6. Wu JP, Zhang Y, Lou XJ et al (2010) Isomer-specific bioaccumulation and trophic transfer of dechlorane plus in the freshwater food web from a highly contaminated site, South China. Environ Sci Technol 44:606-611

7. Shen L, Reiner EJ, MacPherson KA et al (2010) Identification and screening analysis of halogenated norbornene flame retardants in the Laurentian Great Lakes: dechloranes 602, 603, and 604. Environ Sci Technol 44:760-766 
8. USEPA. United States Environmental Protection Agency (2004) High production volume (HPV) challenge program. http://www. epa.gov/HPV/pubs/summaries/dechlorp/c15635tp.pdf

9. Muir DCG, Howard PH (2006) Are there other persistent organic pollutants? A challenge for environmental chemists. Environ Sci Technol 40:7157-7166

10. Möller A, Xie Z, Sturm R et al (2010) Large-scale distribution of dechlorane plus in air and seawater from the Arctic to Antarctica. Environ Sci Technol 44:8977-8982

11. Brock WJ, Schroeder RE, McKnight CA et al (2010) Oral repeat dose and reproductive toxicity of the chlorinated flame retardant dechlorane plus. Int J Toxicol 29:582-593

12. Wu B, Liu S, Guo X et al (2012) Responses of mouse liver to dechlorane plus exposure by integrative transcriptomic and metabonomic studies. Environ Sci Technol 46:10758-10764

13. Wang B, Iino F, Huang J et al (2010) Dechlorane plus pollution and inventory in soil of Huai'an City, China. Chemosphere 80:1285-1290

14. Wang DG, Yang M, Qi H et al (2010) An Asia-specific source of dechlorane plus: concentration, isomer profiles, and other related compounds. Environ Sci Technol 44:6608-6613

15. Li XM, Li YM, Zhang QH et al (2011) Evaluation of atmospheric sources of PCDD/Fs, PCBs and PBDEs around a steel industrial complex in northeast China using passive air samplers. Chemosphere 84:957-963

16. Li YM, Geng DW, Liu FB et al (2012) Study of PCBs and PBDEs in King George Island, Antarctica, using PUF passive air sampling. Atmos Environ 51:140-145

17. Ding L, Li YM, Wang P et al (2013) Spatial concentration, congener profiles and inhalation risk assessment of PCDD/Fs and PCBs in the atmosphere of Tianjin, China. Chin Sci Bull 58:971-978

18. Zhang HD, Wang P, Li YM et al (2013) Assessment on the occupational exposure of manufacturing workers to dechlorane plus through blood and hair analysis. Environ Sci Technol 47:10567-10573
19. Shang HT, Wang P, Wang T et al (2013) Bioaccumulation of PCDD/Fs, PCBs and PBDEs by earthworms in field soils of an E-waste dismantling area in China. Environ Int 54:50-58

20. Ren NQ, Sverko E, Li YF et al (2008) Levels and isomer profiles of dechlorane plus in Chinese air. Environ Sci Technol 42:6476-6480

21. Zhao Z, Zhong GC, Moeller A et al (2011) Levels and distribution of dechlorane plus in coastal sediments of the Yellow Sea, North China. Chemosphere 83:984-990

22. Ma WL, Liu LY, Hong QA et al (2011) Dechlorane plus in multimedia in northeastern Chinese urban region. Environ Int 37:66-70

23. Jia HL, Sun YQ, Liu XJ et al (2011) Concentration and Bioaccumulation of dechlorane compounds in coastal environment of Northern China. Environ Sci Technol 45:2613-2618

24. Wang DG, Alaee M, Sverko E et al (2011) Analysis and occurrence of emerging chlorinated and brominated flame retardants in surficial sediment of the Dalian costal area in China. J Environ Monit 13:3104-3110

25. Shen L, Reiner EJ, Macpherson KA et al (2011) Dechloranes $602,603,604$, dechlorane plus, and chlordene plus, a newly detected analogue, in tributary sediments of the laurentian Great Lakes. Environ Sci Technol 45:693-699

26. Sverko E, Tomy GT, Marvin CH et al (2008) Dechlorane plus levels in sediment of the lower Great Lakes. Environ Sci Technol 42:361-366

27. Zhang Y, Luo XJ, Wu JP et al (2010) Contaminant pattern and bioaccumulation of legacy and emerging organhalogen pollutants in the aquatic biota from an e-waste recycling region in South China. Environ Toxicol Chem 29:852-859

28. Guerra P, Fernie K, Jimenez B et al (2011) Dechlorane plus and related compounds in peregrine falcon (Falco peregrinus) eggs from Canada and Spain. Environ Sci Technol 45:1284-1290 